\title{
Functional assessment of the right ventricle in patients with bronchial asthma of various severity
}

\author{
Grzegorz Mincewicz' ${ }^{1}$ Grzegorz Siergiejko², Marek Piepiorka³, Agnieszka Świdnicka-Siergiejko ${ }^{4}$, Zenon Siergiejko \\ Grzegorz Krzykowski ${ }^{6}$
}

\author{
${ }^{1}$ Department of Molecular Biology, University of Gdansk, Gdansk, Poland \\ ${ }^{2}$ Department of Paediatrics, Gastroenterology, Hepatology, Nutrition and Allergology, Medical University of Bialystok, Bialystok, Poland \\ ${ }^{3}$ Department of Cardiology, Specialist Hospital, Wejherowo, Poland \\ ${ }^{4}$ Department of Gastroenterology and Internal Medicine, Medical University of Bialystok, Bialystok, Poland \\ ${ }^{5}$ Respiratory System Diagnostic and Bronchoscopy Department, Medical University of Bialystok, Bialystok, Poland \\ ${ }^{6}$ WSB University, Gdansk, Poland
}

Adv Dermatol Allergol 2021; XXXVIII (1): 52-56

DOI: https://doi.org/10.5114/ada.2021.104278

\begin{abstract}
Introduction: Pulmonary artery hypertension and its consequences still constitutes an underestimated clinical problem in asthma patients and its non-invasive early detection may influence proper treatment.

Aim: To non-invasively examine the pulmonary artery flow parameters and right ventricular function in patients with asthma of various severity.

Material and methods: The analysis of parameters of echocardiography and first-pass and gated radionuclide angiography, and baseline examination in 31 patients with bronchial asthma and 16 healthy controls.

Results: Patients with severe asthma had higher mean pulmonary artery pressure (MPAP) compared to the healthy controls. The subgroup analysis of patients who suffered from asthma in their childhood showed that individuals with severe asthma were characterized by significantly higher MPAP than those with the mild/moderate condition $(19.16 \pm 7.51 \mathrm{~mm} \mathrm{Hg}$ vs. $5.0 \pm 1.15 \mathrm{~mm} \mathrm{Hg}, p=0.025)$. Gated, but not first-pass, radionuclide angiography revealed that individuals with severe asthma were characterized by a lower right ventricular ejection fraction (RVEF). Further analysis of the subgroup of patients in whom the initial manifestation of dyspnoea occurred no earlier than 6 years prior to the study showed that the RVEF of individuals with severe asthma was significantly lower compared to those with mild/moderate asthma ( $39.8 \pm 4.79 \%$ vs. $51.4 \pm 8.65 \%, p=0.019)$.

Conclusions: The pulmonary artery pressure in patients with severe asthma is significantly higher than in healthy individuals; in contrast, these two groups did not differ significantly in terms of the right ventricular echocardiographic characteristics. Gated radionuclide angiography, but not the first-pass technique, allowed for the detection of subtle right ventricular ejection fraction changes in asthma patients.
\end{abstract}

Key words: asthma, echocardiography.

\section{Introduction}

Chronic pulmonary disorders can lead to pulmonary artery hypertension and chronic cor pulmonale. Alveolar hypoxia is the most important determinant of increased pulmonary resistance. Persistent hypoxia leads to structural changes in the wall of pulmonary vessels and their stenosis or complete impatency. Moreover, chronic hypoxia stimulates bone marrow to enhanced erythropoiesis with a resultant increase in blood viscosity and pulmonary vascular resistance $[1,2]$.
Although chronic obstructive pulmonary disease is the most frequent cause of cor pulmonale [3], also bronchial asthma can predispose to the development of pulmonary artery hypertension [4]. These complications can increase the risk of cardiovascular mortality in asthma patients [5-8]. Nevertheless, the prevalence of pulmonary artery hypertension and its consequences still constitutes an underestimated clinical problem in asthma patients. However, early detection of pulmonary artery hypertension allows for the implementation of proper

Address for correspondence: Grzegorz Siergiejko MD, PhD, Department of Paediatrics, Gastroenterology, Hepatology, Nutrition and Allergology, Medical University of Bialystok, Poland, e-mail: paratasman@op.pl Received: 1.08.2018, accepted: 7.07.2019. 
treatment, and periodic control of pulmonary artery pressure enables control of its effectiveness.

\section{Aim}

The aim of this study was to non-invasively examine the pulmonary artery flow parameters and right ventricular function in patients with asthma of various severity. To achieve these goals, we used two methods based on different physical assumptions, echocardiography and radionuclide angiography.

\section{Material and methods}

\section{Patients}

The protocol of the study was approved by the Local Bioethical Committee of the Medical University of Gdansk and performed in accordance with the Helsinki Declaration of 1975 as revised in 2000. All the participants gave their written informed consent to take part in the project. The study included 31 patients with bronchial asthma treated at the University Clinical Centre in Gdansk, and 16 healthy controls. Based on international guidelines [9], the patients with asthma were divided into two subgroups: 1 ) individuals with mild or moderate chronic asthma ( $n=12$; 9 women and 3 men; mean age: 44.1 years, range: $22-64$ years), and 2 ) patients with severe chronic asthma ( $n=19 ; 10$ women and 9 men; mean age: 42.5 years, range: $28-48$ years). The control group, considered during the analysis of echocardiographic findings, included 16 individuals without respiratory and cardiovascular pathologies (3 women and 13 men; mean age: 39.3 years, range: $23-50$ years).

\section{Basic tests}

Detailed history obtained from all patients with asthma included information on the time since the first episode of dyspnoea, duration of anti-asthmatic treatment, other atopic comorbidities, occurrence of asthma in childhood, and familial occurrence of asthma. Moreover, complete blood count and acid-base balance parameters were determined in all the patients.

\section{Echocardiographic examination}

Echocardiographic examination was conducted with Sonos 1500 (Hewlett Packard) ultrasonograph with a 2/2.5 MHz probe. Three records of systolic pulmonary arterial flow were obtained, and the one characterized by peak flow velocity $\left(\mathrm{V}_{\max }\right)$ was considered during further analysis. The acceleration time (AcT), i.e. the interval between the onset of systolic pulmonary arterial flow and $V_{\max }$, and the right ventricular ejection time (RVET), defined as the interval between the onset and the end of the systolic flow, were read from the curve of systolic pulmonary arterial flow. Subsequently, normalized val- ues of these parameters were calculated by dividing the crude values by the square root of R-R interval expressed in seconds. Moreover, the AcT to RVET ratio was calculated. Finally, mean pulmonary artery pressure (MPAP) was calculated on the basis of the formula: MPAP $=-0.5$ $\times$ AcT $+80 \mathrm{~mm} \mathrm{Hg}$.

\section{First-pass radionuclide angiography}

The examination was conducted with Orbiter (Siemens) gamma-camera and Gamma Vision-32 (Ortec) computer software. The patient was placed in a supine position, and technetium isotope Tc-99m-DTPA at a dose corresponding to $15 \mathrm{mCi}(555 \mathrm{MBq})$ was injected into the right basilic vein in a bolus. The results were recorded in the $45^{\circ}$ left anterior oblique (LAO) projection. Points corresponding to the end-diastole (ED) and end-systole (ES) were identified on the time-activity curve during 2-4 consecutive cycles of the right ventricle. The right ventricular ejection fraction (RVEF) was calculated from the formula: RVEF $=\left(N_{E D}-N_{E S}\right) / N_{E D}$, where $N_{E D}$ and $N_{E S}$ corresponded to the sum of end-diastolic and end-systolic frames, respectively. Moreover, the right ventricle-pulmonary artery and the pulmonary artery-left ventricle transit times were determined.

\section{Gated radionuclide angiography}

The examination was conducted with Diacam (Siemens) gamma-camera and ICON version 5.2 (ICON Medical Imaging) software. The patient was placed in a supine position, and three electrocardiographic leads were placed in the right and left axillary fossa and in the right upper abdominal quadrant. The in vivo labelling of patient's erythrocytes was obtained by two consecutive injections: methylene diphosphonate (MDP), followed by technetium isotope Tc-99m- $\mathrm{O}_{4}$ at a dose corresponding to $25 \mathrm{mCi}(925 \mathrm{MBq})$ given $30 \mathrm{~min}$ thereafter. The recording was started $15 \mathrm{~min}$ after the radionuclide administration. The measurements were taken at the $30-40^{\circ} \mathrm{LAO}$ projection with ECG-gated acquisitions. The frame mode was used during recording with each cardiac cycle divided into 24 sequences. The end-systolic and end-diastolic borders of the right ventricle were determined manually, and the right ventricular ejection fraction was calculated on the basis of the time-activity curve using the formula mentioned above.

\section{Statistical analysis}

Normal distribution of continuous variables was verified with the Kolmogorov-Smirnov test. Statistical characteristics of the continuous variables were presented as arithmetic means and their standard deviations (SD). The Student $t$-test for independent variables and oneway ANOVA with the Tukey post-hoc test were used for intergroup comparisons of the continuous variables. The distributions of qualitative variables were compared 
with the Pearson's $\chi^{2}$ test or the Fisher exact test. All the calculations were carried out with Statistica 10 package (StatSoft, Tulsa OK, USA), with the level of statistical significance set at $p \leq 0.05$.

\section{Results}

Patients with severe asthma and those with mild or moderate asthma did not differ significantly in terms of the time elapsed from the initial episode of dyspnoea and duration of treatment. Moreover, no significant intergroup differences in mean erythrocyte count, haemoglobin concentration, haematocrit level, $\mathrm{pH}$, and $\mathrm{pCO}_{2}$ of peripheral blood were documented. However, significantly lower mean levels of $\mathrm{pO}_{2}$ and $\mathrm{SAT} \mathrm{O}_{2} \%$ were observed in the severe asthma group (Table 1).

The only significant intergroup difference in echocardiographic findings pertained to higher mean pulmonary artery pressure (MPAP) documented in patients with severe asthma compared to the healthy controls (Table 2). Aside from the severity of asthma, also the history of childhood asthma proved to be a significant determinant of increased MPAP: the subgroup analysis of patients who suffered from asthma in their childhood showed that individuals with severe asthma were characterized by significantly higher MPAP than those with the mild/moderate condition (19.16 $\pm 7.51 \mathrm{~mm} \mathrm{Hg}$ vs. $5.0 \pm 1.15 \mathrm{~mm} \mathrm{Hg}, p=0.025$ ).

The analysis of radionuclide angiography findings revealed that individuals with severe asthma were char-

Table 1. Statistical characteristics of the course of bronchial asthma, morphological parameters of peripheral blood, and acid-base balance in patients with mild/moderate and severe asthma

\begin{tabular}{|c|c|c|c|}
\hline Parameter & $\begin{array}{c}\text { Mild/moderate } \\
\text { asthma } \\
(n=12)\end{array}$ & $\begin{array}{l}\text { Severe } \\
\text { asthma } \\
(n=19)\end{array}$ & $P$-value \\
\hline \multicolumn{4}{|c|}{ Time since the initial episode of dyspnoea: } \\
\hline$<6$ years & $5(41.7 \%)$ & $4(21.1 \%)$ & \multirow[t]{2}{*}{0.204} \\
\hline$\geq 6$ years & $7(58.3 \%)$ & $15(78.9 \%)$ & \\
\hline \multicolumn{4}{|l|}{ Duration of treatment: } \\
\hline$<5$ years & $4(33.3 \%)$ & $6(31.6 \%)$ & \multirow[t]{2}{*}{0.610} \\
\hline$\geq 5$ years & $8(66.7 \%)$ & $13(68.4 \%)$ & \\
\hline Erythrocytes $\left[\times 10^{6} / \mu l\right]$ & $4.6 \pm 0.33$ & $4.8 \pm 0.44$ & 0.276 \\
\hline Haemoglobin [g/dl] & $13.8 \pm 1.01$ & $14.3 \pm 1.35$ & 0.276 \\
\hline Haematocrit (\%) & $41.4 \pm 2.23$ & $42.8 \pm 4.09$ & 0.273 \\
\hline $\mathrm{pH}$ & $7.4 \pm 0.02$ & $7.4 \pm 0.04$ & 0.987 \\
\hline $\mathrm{pCO}_{2}[\mathrm{KPa}]$ & $37.6 \pm 2.82$ & $36.8 \pm 3.76$ & 0.553 \\
\hline $\mathrm{pO}_{2}[\mathrm{KPa}]$ & $71.6 \pm 6.37$ & $65.2 \pm 8.71$ & 0.038 \\
\hline $\mathrm{SAT} \mathrm{O}_{2}(\%)$ & $93.8 \pm 1.44$ & $91.9 \pm 2.66$ & 0.026 \\
\hline
\end{tabular}

acterized by lower (at a threshold of the statistical significance) right ventricular ejection fraction (Table 3). Further analysis of the subgroup of patients in whom initial manifestation of dyspnoea occurred no earlier than 6 years prior to the study showed that the RVEF of individuals with severe asthma was significantly lower compared to those with mild/moderate asthma (39.8 $\pm 4.79 \%$ vs. 51.4 $\pm 8.65 \%, p=0.019$ ).

\section{Discussion}

Our study revealed that the level of pulmonary artery pressure in patients with severe asthma is significantly higher than in healthy individuals. This finding is consistent with the results of previous studies of the prevalence of pulmonary artery hypertension in patients with

Table 2. Statistical characteristics of echocardiographic findings in patients with mild/moderate and severe asthma and in healthy controlsw

\begin{tabular}{lccc}
\hline Parameter & $\begin{array}{c}\text { Mild/moderate } \\
\text { asthma } \\
(n=12)\end{array}$ & $\begin{array}{c}\text { Severe } \\
\text { asthma } \\
(n=19)\end{array}$ & $\begin{array}{c}\text { Healthy } \\
\text { controls } \\
(n=16)\end{array}$ \\
\hline MPAP [mm Hg] & $12.3 \pm 10.93$ & $15.5 \pm 6.56^{*}$ & $10.3 \pm 5.18$ \\
\hline RVET [s] & $315.9 \pm 25.4$ & $303.7 \pm 37.3$ & $307.8 \pm 27.53$ \\
\hline AcT [s] & $149.6 \pm 26.06$ & $139.4 \pm 14.96$ & $141.9 \pm 13.72$ \\
\hline RVETnorm [s] & $335.5 \pm 47.04$ & $338.1 \pm 36.63$ & $337.8 \pm 28.59$ \\
\hline AcTnorm [s] & $160.4 \pm 27.97$ & $155.6 \pm 20.35$ & $155.7 \pm 18.29$ \\
\hline AcT/RVET & $0.5 \pm 0.08$ & $0.5 \pm 0.07$ & $0.5 \pm 0.04$ \\
\hline
\end{tabular}

*Significantly higher than in the controls $(p=0.015)$. MPAP - mean pulmonary artery pressure, RVET - right ventricular ejection time, ACT - acceleration time, $R V E T_{\text {norm, }}, A C T_{\text {norm }}-$ RVET and ACT normalized by dividing the crude values by the square root of $R$ - $R$ interval(s).

Table 3. Statistical characteristics of first-pass and gated radionuclide angiography findings in patients with mild/ moderate and severe asthma

\begin{tabular}{lccc}
\hline Parameter & $\begin{array}{c}\text { Mild/moderate } \\
\text { asthma }(n=12)\end{array}$ & $\begin{array}{c}\text { Severe asthma } \\
(n=19)\end{array}$ & $P$-value \\
\hline \begin{tabular}{l} 
First-pass radionuclide angiography: \\
\hline RVEF (\%)
\end{tabular} & $45.7 \pm 5.03$ & $46.9 \pm 5.85$ & 0.569 \\
\hline LVEF (\%) & $55.4 \pm 6.67$ & $54.6 \pm 6.63$ & 0.746 \\
\hline $\begin{array}{l}\text { Right ventricle- } \\
\text { pulmonary } \\
\text { transit [s] }\end{array}$ & $3.5 \pm 0.7$ & $3.5 \pm 0.81$ & 0.931 \\
\hline $\begin{array}{l}\text { Pulmonary-left } \\
\text { ventricle transit }\end{array}$ & $3.3 \pm 1.3$ & $3.1 \pm 1.01$ & 0.792 \\
[s] & & \\
\hline $\begin{array}{l}\text { Gated radionuclide angiography: } \\
\text { RVEF (\%) }\end{array}$ & & \\
\hline LVEF (\%) & $58.1 \pm 7.66$ & $43.3 \pm 6.84$ & 0.089 \\
\hline
\end{tabular}

$R V E F$ - right ventricular ejection fraction, LVEF - left ventricular ejection fraction. 
severe obstructive changes; according to the literature, the prevalence of pulmonary artery hypertension markers, right ventricular and right atrial hypertrophy, corresponds to $27.7 \%$ and $23.6 \%$, respectively in this group [10]. However, our patients with asthma did not differ significantly from healthy controls in terms of echocardiographic parameters of the right ventricular contractility. This raised the question if this lack of significant intergroup differences was associated with normal right ventricular contractility of asthma patients, or rather resulted from insufficient sensitivity of echocardiography in detection of potential abnormalities. This was explained by the results of radionuclide angiography. For ethical reasons, healthy controls were not included in this part of our experiment, which was limited to comparative analysis of the cardiac function in subgroups of patients with severe and mild/moderate asthma.

The first-pass angiography did not reveal significant intergroup differences of RVEF. In contrast, the gated angiography showed that the RVEF of individuals with severe asthma is lower (at a threshold of the statistical significance) than that of patients with mild/moderate asthma. Moreover, using this method we proved that the subgroup of individuals with severe asthma and less than 6 years of dyspnoea is characterized by significantly lower RVEF than the other patients. Consequently, the gated radionuclide angiography can identify a subgroup of patients with rapidly progressing severe chronic asthma and an increased risk of impaired pulmonary flow.

Increased cardiovascular mortality of asthma patients was highlighted in the second part of the last century [5-7]. Initially, this phenomenon was postulated to be of iatrogenic character and result from chronic used of catecholamines, other $\beta_{2}$-agonists, and aminophylline [11-14]. It was revealed that chronic use of these agents can be associated with myocardial injury in the form of focal necrosis or subepicardial myolysis [11-13]. Another type of myocardial necrosis, so-called myocardial contraction band necrosis (MCBN) was also described in patients with bronchial asthma [15]. This type of necrosis is not directly induced by exogenous factors but is caused by mediators released from cardiac mastocytes in response to circulating antigens, antibodies, therapeutic agents, and other substances (e.g. contrasting agents) [16-18].

However, the results of recent molecular studies point to possible common pathogenic pathways of asthma and pulmonary artery hypertension, associated with the activity of the NFAT transcription factor family [19]. In experimental models, these factors were revealed to be involved both in bronchial remodelling and in the remodelling of smaller pulmonary arteries [20-25]. These findings were at least partially confirmed by the results of our study as we revealed that the degree of cardiovascular failure in asthma patients is determined by the severity of their primary condition; compared to patients with mild/moderate asthma, individuals with severe asthma were characterized by significantly lower partial oxygen pressure and oxygen saturation. Consequently, one can suppose that the bronchial remodelling which is associated with severe asthma can be reflected by persistent changes leading to decreased partial oxygen pressure and worse saturation.

This phenomenon can be especially unfavourable in the case of asthma exacerbation. Each asthma attack is associated with reduced bronchial airflow and resultant "air trapping" as well as with the disorders of ventilation and perfusion, development of hypoxia and subsequent hypercapnia [26]. Hypoxia is reflected by a contraction in small muscular pulmonary arteries, leading the pulmonary artery hypertension $[27,28]$. The increase in pulmonary vascular resistance results in higher right ventricular overload $[29,30]$ and subsequent, life-threatening deterioration of cardiovascular and respiratory capacity. Our finding on the usefulness of gated radionuclide angiography in the early detection of pulmonary flow impairment in patients with rapidly progressing asthma seems especially valuable in this context.

Undoubtedly, our study suffers from two important limitations. The first of them is relatively small size of the group of asthma patients. The second limitation pertains to the lack of the control group in the part of our study dealing with the usefulness of radionuclide angiography. Nevertheless, our study confirmed that patients with asthma are at risk of pulmonary artery hypertension and right ventricular failure, which both can be detected by means of gated radionuclide angiography.

\section{Conclusions}

Our study revealed that the pulmonary artery pressure in patients with severe asthma is significantly higher than in healthy individuals; in contrast, these two groups did not differ significantly in terms of the right ventricular echocardiographic characteristics. Gated radionuclide angiography is superior to the first-pass technique in the detection of subtle right ventricular contractility disorders in asthma patients. Moreover, the gated technique allows for the detection of high-risk subgroup of patients with severe chronic asthma, characterized by a low right ventricular ejection fraction and enhanced inflammation of the bronchial tree.

\section{Conflict of interest}

The authors declare no conflict of interest.

\section{References}

1. Bardsley P, Evely R, Howard P. Hypoxic cor pulmonale: a review. Herz 1986; 11: 155-68.

2. Poor HD, Girgis R, Studer SM. World Health Organization Group III pulmonary hypertension. Prog Cardiovasc Dis 2012; 55: 119-27. 
3. Shujaat A, Minkin R, Eden E. Pulmonary hypertension and chronic cor pulmonale in COPD. Int I Chron Obstruct Pulmon Dis 2007; 2: 273-82.

4. Calverley PM, Catterall JR, Shapiro C, Douglas NJ. Cor pulmonale in asthma. Br J Dis Chest 1983; 77: 303-7.

5. Lang DM, Polansky M. Patterns of asthma mortality in Philadelphia from 1969 to 1991. N Engl J Med 1994; 331: 1542-6.

6. Silverstein MD, Reed CE, O'Connell EJ, et al. Long-term survival of a cohort of community residents with asthma. N Engl J Med 1994; 331: 1537-41.

7. Lange P, Ulrik CS, Vestbo J. Mortality in adults with selfreported asthma. Copenhagen City Heart Study Group. Lancet 1996; 347: 1285-9.

8. Omachi TA, Iribarren C, Sarkar U, et al. Risk factors for death in adults with severe asthma. Ann Allergy Asthma Immunol 2008; 101: 130-6.

9. National Asthma Education and Prevention Program. Expert Panel Report 3 (EPR-3): Guidelines for the Diagnosis and Management of Asthma-Summary Report 2007. J Allergy Clin Immunol 2007; 120: S94-138.

10. Chazan R, Droszcz W. Electrocardiographic changes in patients with airway obstruction. Pol Arch Med Wewn 1992; 87: 237-41.

11. Matson JR, Loughlin GM, Strunk RC. Myocardial ischemia complicating the use of isoproterenol in asthmatic children. J Pediatr 1978; 92: 776-8.

12. Kurland G, Williams J, Lewiston NJ. Fatal myocardial toxicity during continuous infusion intravenous isoprotereno therapy of asthma. J Allergy Clin Immunol 1979; 63: 407-11.

13. Lüchtrath $\mathrm{H}$. On the pathology of acute heart failure in bronchial asthma. Virchows Arch A Pathol Anat Histol 1979; 381: 343-52.

14. Spitzer WO, Suissa S, Ernst P, et al. The use of beta-agonists and the risk of death and near death from asthma. N Eng J Med 1992; 326: 501-6.

15. Drislane FW, Samuels MA, Kozakewich $\mathrm{H}$, et al. Myocardial contraction band lesions in patients with fatal asthma: pos sible neurocardiologic mechanisms. Am Rev Respir Dis 1987; 135: 498-501.

16. Marone G, Triggiani M, Cirillo R, et al. Chemical mediators and the human heart. Prog Biochem Pharmacol 1985; 20: 38-54.

17. Marone G, Triggiani M, Cirillo R, et al. IgE-mediated activation of human heart in vitro. Agents Actions 1986; 18: 194-6.

18. Farha S, Sharp J, Asosingh K, et al. Mast cell number, phenotype, and function in human pulmonary arterial hypertension. Pulm Circ 2012; 2: 220-8.

19. Said SI, Hamidi SA, Gonzalez Bosc L. Asthma and pulmonary arterial hypertension: do they share a key mechanism of pathogenesis? Eur Respir J 2010; 35: 730-4.

20. Diehl S, Krahl T, Rinaldi L, et al. Inhibition of NFAT specifically in T cells prevents allergic pulmonary inflammation. J Immunol 2004; 172: 3597-603.

21. Monticelli S, Solymar DC, Rao A. Role of NFAT proteins in IL13 gene transcription in mast cells. J Biol Chem 2004; 279 : 36210-8.

22. Koulmann N, Novel-Chate V, Peinnequin A, et al. Cyclosporin A inhibits hypoxia-induced pulmonary hypertension and right ventricle hypertrophy. Am J Respir Crit Care Med 2006; 174: 699-705.

23. Nakamura Y, Yamauchi K, Inoue H. Novel ribbon-Type NF-AT decoy oligodeoxynucleotides preclude Th2 cytokines expression and airways hyperreactivity in experimental asthma. J Allergy Clin Immunol 2006; 117: S245.
24. Bonnet S, Rochefort G, Sutendra G, et al. The nuclear factor of activated $T$ cells in pulmonary arterial hypertension can be therapeutically targeted. Proc Natl Acad Sci USA 2007; 104: 11418-23.

25. de Frutos S, Spangler R, Alo D, et al. NFATc3 mediates chronic hypoxia-induced pulmonary arterial remodeling with alpha-actin up-regulation. J Biol Chem 2007; 282: 15081-9.

26. Edelson JD, Rebuck AS. The clinical assessment of severe asthma. Arch Intern Med 1985; 145: 321-3.

27. Handa S, Fujii I, Ohonishi S, et al. Strategy to manage pump failure due to chronic pulmonary diseases: pathophysiology and treatment of right ventricular overload. Jpn Circ J 1986; 50: 350-8.

28. Keller CA, Shepard JW Jr, Chun DS, et al. Pulmonary hypertension in chronic obstructive pulmonary disease. Multivariate analysis. Chest 1986; 90: 185-92.

29. Morrison D, Goldman S, Wright AL, et al. The effect of pulmonary hypertension on systolic function of the right ventricle. Chest 1983; 84: 250-7.

30. Schoen FJ. Cardiac pathology in asthma. J Allergy Clin Immunol 1987; 80: 419-23. 